\title{
PROCESOS DE IDENTIFICACIÓN ÉTNICO-CULTURALES. ENSAMBLAJES Y DESARTICULACIONES DESDE LAS TRAYECTORIAS DE JÓVENES PERTENECIENTES A PUEBLOS INDÍGENAS
}

\author{
ETHNIC-CULTURAL IDENTIFICATION PROCESSES. \\ ASSEMBLIES AND DISARTICULATIONS FROM THE TRAJECTORY \\ OF YOUNG PEOPLE WHO BELONG TO INDIGENOUS PEOPLE
}

\author{
Gabriela Garcés Pérez* \\ Universidad de La Frontera \\ Temuco-Chile
}

\section{Ana Figueiredo}

Universidad Academia de Humanismo Cristiano

Santiago-Chile

Recibido febrero de 2021/Received February, 2021

Aceptado junio de 2021/Accepted June, 2021

\begin{abstract}
RESUMEN
El propósito de este trabajo es la articulación de perspectivas teóricas-conceptuales acerca de la identidad étnica-cultural, para la configuración de un enfoque que permite proyectar líneas metodológicas que posibilitan ampliar el rango de comprensión de los procesos actuales de construcción identitaria, considerando al sujeto participante y la vinculación investigador-sujeto como eje del proceso investigativo. Para ello en un primer momento se ponen en diálogo conceptualizaciones respecto de la identidad étnica-cultural acuñadas desde las ciencias sociales, con procesos de subjetivación propuestos desde perspectivas críticas posestructuralistas, poscoloniales y narrativas. Para en un segundo momento, desprender lineamientos metodológicos que consideran la integración de elementos: macrosociales y colectivos; de la narrativa de los sujetos; y de la interacción investigador-sujeto participante. Finalmente se argumenta una propuesta de articulación y ensamblaje de experiencias y temporalidades que abren espacios para la liberación de la potencialidad de los sujetos, y a la vez de desarticulación y neutralización de sus determinaciones, transitando desde una concepción del ser y de identidad sustanciales, de calco y recurrencias que han primado durante la modernidad, hacia una concepción de la diferencia, de lo múltiple, que releva la intensidad y la potencia.
\end{abstract}

Palabas Clave: Identidad cultural, pueblos indígenas, juventud, aproximación participativa.

\begin{abstract}
The purpose of this work is the articulation of theoretical-conceptual perspectives on the ethnic-cultural identity, for the configuration of an approach that allows projecting methodological lines that make possible to expand the range of understanding of the current processes of identity construction, considering the subject who participates and the researcher-subject connection as the axis of the research process. For this, at first, conceptualizations about ethnic-cultural identity coined from the social sciences are put into dialogue, with the processes of subjectivation proposed from the critical poststructuralist, postcolonial, and narrative perspectives; for in a second moment, detach methodological guidelines that consider the integration of elements: macrosocial and collective; of the narrative of the subjects; and the researcher-participant subject interaction. Finally, a proposal for the articulation and assembly of experiences and temporalities is argued, which opens spaces for the liberation of the potentiality of the subjects,
\end{abstract}


and at the same time, for the disarticulation and neutralization of their determinations, moving from a conception of being and substantial identity, of tracing and recurrences, that have prevailed during modernity, towards a conception of difference, of the multiple, that relieves intensity and power.

Key Words: Cultural identity, indigenous people, youth, participatory approach.

\section{AGRADECIMIENTOS}

Este trabajo contó con el apoyo de una beca de doctorado del Centro de Estudios de Conflicto y Cohesión Social (COES; ANID/FONDAP/15130009) atribuida a la primera autora y de un proyecto FONDECYT de Iniciación (ANID/FONDECYT Iniciación / 3160352) atribuido a la segunda autora.

Las autores/as también agradecen el apoyo recibido del Doctorado en Ciencias Sociales de la Universidad de La Frontera y de la beca CONICYT del Ministerio de Educación de Chile (CONICYT/ FONDAP /15110006) durante la preparación de este manuscrito.

\section{INTRODUCCIÓN}

El propósito principal de este trabajo es desarrollar una revisión de enfoques teóricos sobre la identidad étnica-cultural indígena, proponiendo líneas metodológicas que permitan ampliar el rango de comprensión de los procesos actuales de construcción identitaria de jóvenes pertenecientes a pueblos indígenas. El interés surge a partir de experiencias de investigación con comunidades mapuche rurales lafkenche de la Región de la Araucanía Chile desarrolladas durante los años (2016-2017), donde la relevancia de los procesos de movilidad y migración de las generaciones jóvenes, suscitaron nuevas preguntas asociadas a los procesos de construcción identitaria de los jóvenes que emigran desde sus lof o comunidades, a cursar estudios de enseñanza media al pueblo o ciudad cercana, y posteriormente a la capital regional a proseguir estudios de enseñanza superior y/o por la búsqueda de oportunidades laborales. Así lo manifiestan las siguientes citas, de tres personas adultas de la costa lafkenche de la Araucanía:

En la escuelita de Peleco, en Toltén, ahí teníamos un profesor mapuche y quería que todos aprendiéramos a leer y a escribir, después mi madre me internó en Puerto Domínguez, estuve 2 años interno haciendo quinto y sexto, de ahí me fui a la comunidad de vuelta, pensando en trabajar (...) hubo una oportunidad en el gobierno de Eduardo Frei Montalva, que se formaron voluntarios de salud en Temuco, y ahí partí yo en el año 1969 como voluntario de salud en la comunidad. Hacia lo que me gustaba hacer, o sea era como el puente entre la gente que no hablaba español y yo hablaba español y mapudungun (J.L. 64 años).

Para poder estudiar, estuve primero interno en Puerto Saavedra, después en Nueva Imperial igual interno, en el fondo sacaba cuentas que, son como siete años que estuvimos internados. Y después ya de adulto me fui a Temuco a estudiar el técnico en enfermería (B.N, 35 años).

(...) Porque nosotros como mapuches de repente nosotros mismos nos desvalorizamos, no sabíamos hablar mapuche, pero si lo hablábamos más nos trataban mal, y si no nos trataban mal estaba esa discriminación siempre (E.T, 28 años).

Estas trayectorias son comunes a muchos de los jóvenes de pueblos originarios que migran a centros urbanos en Chile (Antileo, 2011, 2014; Aravena, 1999) y en otras latitudes del mundo. Procesos en los cuales estas nuevas generaciones se integran de forma progresiva en la sociedad nacional y los estilos de vida urbanos que le son propios. A este respecto y en relación a lo evidenciado en la literatura académica producida (Aquino y Contreras, 2016; García, 2017; Merino, Webb, Radcliffe, Becerra, y Aillañir, 2020; Oteiza y Merino, 2012; Serrano, 2015; Virtanen, 2010), los jóvenes vivencian una inmersión progresiva en el medio urbano; en el cual afrontan, negocian e internalizan valores, normas, costumbres, significados y racionalidades que se diferencian de los entornos de socialización temprana.

En relación con este proceso, emerge la pregunta por las formas de acercamiento y compresión de estas trayectorias considerando sus distintas dinámicas y elementos implicados, poniendo en el centro al sujeto quien experimenta procesos de re-significación y ensamblaje de elementos socioculturales diversos. En este contexto la pregunta que interesa abordar es la siguiente: ¿De qué forma podemos comprender la configuración de las identidades étnico-culturales actuales de los jóvenes 
pertenecientes a pueblos indígenas? Y desde una perspectiva poscolonial y situada ¿Qué papel juega el propio proceso de indagación en las trayectorias y procesos de identificación de los jóvenes?

Para ello, en el primer apartado se ponen en diálogo diversas perspectivas críticas que relevan la matriz de poder que subyace a las definiciones sobre identidad étnica y cultural que históricamente se han realizado de los otros; desde perspectivas posestructuralistas, poscoloniales, así como desde las epistemologías feministas, y decoloniales latinoamericanas, configurando un enfoque teórico-conceptual. A partir de ello, en un segundo momento se desprenden líneas de abordaje metodológico prefigurando al proceso investigativo como un lugar de intersección y articulación de niveles de realidad que permite develar opresiones, y potencialidades que posibiliten el despliegue del ser desde su capacidad de crear, y de esta forma posicionar al sujeto como protagonista de su propio destino.

\section{A. IDENTIDAD ÉTNICO-CULTURAL}

Desde las ciencias sociales la identidad cultural ha sido abundantemente abordada y discutida. De forma particular la antropología en su evolución histórica impulsada por el estudio de la diversidad y los fenómenos culturales e identitarios de los pueblos originarios y no occidentales, ha iluminado algunas cuestiones claves que han proyectado programas de investigación en el campo antropológico y en otros campos disciplinarios. En los inicios del siglo XX, fueron refutadas las teorías evolucionistas que postulaban la irracionalidad del hombre primitivo y de la mentalidad prelógica. Boas planteó que "tanto el civilizado como el primitivo aceptan inconscientemente las pautas de su cultura" (Boas, 1964, p. 14), aflorando con fuerza la noción de diversidad cultural. Desde esta época se dio un fuerte énfasis a la investigación basada en evidencia; el trabajo de campo etnográfico de "estar allî́", comprender las pautas y patrones culturales desde su propio desarrollo histórico, vinculándolas a la cultura como un todo interdependiente. Durante la primera mitad del siglo XX proliferaron distintas escuelas que estudiaron al otro cultural $\mathrm{y}$, junto con ello, fueron acuñadas múltiples nociones de cultura de las que, a su vez, se derivaron nociones de identidad (Aguirre-Baztán, 2018). Para dimensionar esta diversidad de conceptos, Kuper (2001) señala que entre 1920 y 1950 los científicos sociales norteamericanos crearon no menos de 157 definiciones de cultura: desde algunas que enfatizaban en la difusión histórico-geográfica de elementos culturales, estructural-funcionalista, materialistas, ecológicas, configuracionistas de la personalidad, simbólicas, etc., Sin embargo se advierte que todas estas nociones incluida la célebre definición semiótica-interpretativa de Geertz (1987), conciben a la cultura como contenidos/elementos sustantivos específicos traspasados mediante procesos de socialización transgeneracionales:

\begin{abstract}
Norma de significados transmitidos históricamente, personificados en símbolos, un sistema de concepciones heredadas expresadas en formas simbólicas por medio de las cuales los hombres se comunican, perpetúan y desarrollan su conocimiento de la vida y sus actitudes con respecto a esta (p. 89).
\end{abstract}

En esta línea entonces, un nuevo aspecto relevante que emerge a la luz de los fenómenos de globalización propios de la modernidad contemporánea, es la problematización de esta noción esencialista de la cultura (y de la identidad étnico-cultural) que primó durante gran parte del siglo XX (siguiendo propósitos ético-políticos relacionados con la necesidad de una antropología de salvataje de las culturas en sus modos "originales"). A este respecto, Barth (1976), observando que los grupos étnicos están en constante transformación e interacción con otras sociedades, plantea que estos deben considerarse como una forma de organización social de las diferencias culturales, ya que "los rasgos que son tomados en cuenta no son la suma de diferencias 'objetivas', sino solamente aquellos que los actores mismos consideran significativos" (Barth, 1976, p. 15). De aquí la importancia central de la autoadscripción y de la heteroadscripción categorial en esta teoría, es decir, de la definición que realizan los propios sujetos colectivos e individuales. A partir de estos planteamientos, se reconoce a Barth la distinción entre cultura (como contenidos específicos) e identidad étnica (autoadscrita y en constante transformación), procesos que presentarían dinámicas de trasformación y persistencia en el tiempo diferenciados (Poutignat y Streiff-Fernant, 1995).

En diálogo con esta distinción y desde los estudios culturales, Hall (2003) propone un concepto de identidad estratégico y posicional, en el que las identidades nunca se unifican. Plantea que 
en los tiempos de la modernidad tardía, están cada vez más fragmentadas y fracturadas; nunca son singulares, sino construidas de múltiples maneras mediante discursos, prácticas y posiciones diferentes, a menudo cruzadas y antagónicas. Están sujetas a una historización radical, y en un constante proceso de cambio y transformación. El autor señala entonces, que es preciso situar los debates acerca de la identidad dentro de todos esos desarrollos y prácticas históricamente específicos que perturbaron el carácter relativamente "estable" de muchas poblaciones y culturas, sobre todo en relación con los procesos de globalización, coextensos con la modernidad, y los procesos de migración forzada y "libre" convertidos en un fenómeno global del llamado mundo "poscolonial" (Hall y Du Gay, 2006).

Estos planteamientos que reformulan la noción de identidad étnico-cultural y de cultura, son desarrollados con mayor fuerza argumentativa desde la antropología posmoderna, donde el estudio de la diversidad cultural se traslada desde lo exótico o lejano, al análisis de la sociedad occidental contemporánea; la mirada de la antropología se vuelca sobre su propia praxis. Grimson (2011) señala que la comprensión del mundo cultural del otro, como del nuestro, es posible en un ejercicio de entrada y salida, afirmando que "tenemos que comprender nuestra cultura y nuestro mundo, pero solo podremos hacerlo saliendo de ellos, desde afuera. Y solo podremos salir de ellos si los comprendemos desde adentro" (p. 51). En este contexto asevera que la antropología "escoge vivir y desplegarse en la encrucijada misma, saliendo y volviendo a entrar, comprendiendo en la comparación" (p. 51). A su vez refiere que "visibilizar nuestras antropologías implica enunciar, en nuestro espacio público, que no podemos permanecer en la ignorancia de la diferencia, en la negación de la multiplicidad de lenguajes corporales, musicales, de formas de imaginación, de estructuras de sentimientos" (Grimson, 2011, p. 51). Estos planteamientos fundamentan a la cultura como dimensión de lo real, la que es producida y se torna visible desde una reflexión simultánea, recursiva y autoconsciente, encarnada en el proceso de comprensión y conocimiento.

\section{Subjetividades de la sociedad moderna contemporánea}

Muchas de las conceptualizaciones de cultura e identidad históricamente fueron acuñadas bajo el alero de un quehacer científico neutral, que desde la academia define y conceptualiza al otro invisibilizando la reproducción de las posiciones de poder en esa práctica. Muchas de estas investigaciones antropológicas formaron parte de proyectos de fortalecimiento de las identidades nacionales en la época de la posguerra, en Estados Unidos y Europa (Neiburg y Goldman, 2001). A este aspecto, Rose (1990) señala que en el siglo XX desde las ciencias psicológicas emerge un saber experto: "el gobierno del alma", cuya finalidad es la administración de las subjetividades para regular la conducta de los ciudadanos, sus capacidades y predisposiciones mentales. Advertimos entonces, que esta forma de control se extrapola también a otras ciencias sociales como la antropología y la sociología, desde donde se generaron mecanismos de regulación de las sociedades y grupos culturales no occidentales a partir del control y gestión de las identidades. Lo que en un caso ha implicado la patologización-medicalización de los problemas, en el otro se refleja en la creación de tecnologías neocoloniales de dominación, en el integracionismo como política de los Estados-nacionales y la exotización funcional de la otredad cultural.

Considerando estos aspectos, resulta importante analizar cómo son producidas las subjetividades de los sujetos contemporáneos latinoamericanos. Desde la teoría crítica se ha planteado que la sociedad moderna ha generado mecanismos de contención del cambio social a partir de la captura del sujeto (Marcuse, 1993): "El control se ha osificado en las instituciones y en las estructuras mentales de los sujetos, al verse reducida la dimensión donde reside el poder crítico de la razón" (Ibíd., p. 41). En esta línea, Foucault (2008) aduce una microfísica del poder que las instituciones ponen en juego, "pero cuyo campo de validez se sitúa en cierto modo entre esos grandes funcionamientos y los propios cuerpos con su materialidad y sus fuerzas" (p. 33). El autor pone en evidencia las tecnologías de disciplinamiento corporal que ejercen las instituciones, principalmente los Estados nacionales sobre los sujetos (Ibíd., 2008). Para Foucault (1988), el ser y la identidad se define en "la lucha en torno a la pregunta por quién somos nosotros" (p. 5), estas luchas apuntan a lo que denomina una técnica y forma de poder que emerge en la vida cotidiana, "categoriza y marca al individuo por su propia individualidad, lo une a su propia identidad, le impone una ley de verdad que él tiene que reconocer y al mismo tiempo, otros tienen que reconocer en él. Es una forma de poder 
que construye sujetos individuales" (Ibíd., p. 6). En esta línea, Rose (1990) plantea que las capacidades personales y subjetivas de los ciudadanos "han sido incorporadas al ámbito y las aspiraciones de los poderes públicos; la subjetividad ha entrado en los cálculos de las fuerzas políticas sobre el estado de la nación, sobre los problemas y posibilidades que enfrenta un país" (p. 1-2). Refiere a la administración de la subjetividad como tarea central para la organización moderna.

Dufour (1998), por su parte, sostiene que en la época de las democracias liberales se dan formas de destitución subjetiva que se revelan por medio de múltiples síntomas: la aparición de fallas psíquicas, la eclosión de un malestar en la cultura, la multiplicación de actos de violencia, como elementos de nuevas formas de alienación y de desigualdad. Plantea que en la posmodernidad la subjetividad se construye y reconstruye adoleciendo del otro como referente; la autonomía jurídica y la libertad mercantil son absolutamente congruentes con la definición autorreferencial del sujeto. Lo que se refleja en que las sociedades posmodernas confluyan cada vez con más frecuencia técnicas de acción sobre uno mismo, "verdaderas prótesis identitarias que vienen a aplicarse en el lugar donde opera la destitución del sujeto" (Ibíd., p. 3-4). Asimismo, las redes sociales, el internet, constituyen una forma inédita de control social, en ellas voluntariamente nos entregamos y "contribuimos al panóptico digital, en la medida en que nos desnudamos y exponemos" (Han, 2013, p. 94). El consumo y las redes sociales ofrecen nuevas formas de participación e integración social a los sujetos.

Respecto de los procesos globalizadores, Castro-Gómez (1998) plantea que estos convierten a todos y cada uno de los sujetos en agentes de la globalización, en la medida en que se vinculan formalmente a las redes mundiales de intercomunicación. Señala que los estudios culturales en América Latina han mostrado de forma contundente que la globalización es apropiada y encarnada por los distintos sujetos individuales y colectivos reconfigurando las identidades (Ibíd., 1998). Grossberg (1996), a su vez, problematiza el componente de generalización de estos presupuestos señalando que la subjetividad en las sociedades humanas siempre se inscribe o distribuye dentro de códigos culturales de diferencias, que organizan a los sujetos mediante la definición de identidades sociales:
En otras palabras, aunque todos los individuos existen dentro de los estratos de la subjetividad, también están situados en determinadas posiciones, cada una de las cuales permite y restringe las posibilidades de la experiencia, de representar esas experiencias y de legitimar esas representaciones. Así, la identidad es una cuestión de poder social, y su articulación, su anclaje en el cuerpo de la población misma (Grossberg citado en Hall y du Gay, 2006, p. 167).

Resulta interesante sumar a esta discusión los planteamientos de la antropóloga Ortner (2006), quien concibe a la subjetividad como base de la "agencia", en tanto elemento necesario para comprender por qué las personas obran (tratan de obrar) sobre el mundo, aun cuando son objeto de ese obrar. No obstante, esta autora señala que la agencia no es concebida como una voluntad natural u originaria, sino que adopta la forma de deseos e intenciones específicas dentro de una matriz de subjetividad (Ortner, 2006). En esta línea, Ortner (1999) interpela el análisis interpretativista de Geertz; la descripción densa que adolece de un componente crítico, proponiendo entonces la categoría de resistencia densa. Ella señala: "Las dimensiones menos exóticas del poder, que (Geertz) reconoce como operativas, aparecen tan subordinadas al argumento cultural que quedan virtualmente abandonadas" (Ortner, 1999, p. 139). En este contexto de discusión, y recapitulando los planteamientos de los autores citados, en el análisis de las subjetividades contemporáneas cobra importancia atender los distintos mecanismos de poder que organizan a la sociedad en sus distintos niveles y que instituyen procesos para la producción y reproducción de las subjetividades. Estos mecanismos de poder atraviesan las dinámicas relacionales entre las sociedades y grupos específicos generando procesos de diferenciación, integración y exclusión social. Por otro lado, los distintos grupos sociales y sujetos individuales y colectivos, manifiestan su capacidad de agencia mediante la producción de nuevas subjetividades y acciones como respuestas de empoderamiento y resistencia desde el interior de las sociedades.

\section{La identidad del otro culturalmente diverso}

Como ya ha sido señalado, los procesos de construcción identitaria comportan aspectos conflictivos o dilemáticos, toda vez que se encuentran atravesados por relaciones de poder que mediatizan 
los procesos de subjetivación. Estos han estado históricamente asociados a las relaciones desiguales entre los Estados-sociedades nacionales y los pueblos originarios que acontecen e impactan las trayectorias de vida de las generaciones jóvenes en distintas regiones del mundo así como en la actual sociedad chilena contemporánea (Bello, 2007, 2016; Segato, 2002). Por tanto cobra interés para la comprensión de la configuración identitaria, visualizar estas relaciones que operan en distintos niveles sobre ellos: epistemológico, estructural, cultural-simbólico y subjetivo-corporal (Foucault, 2008, 2010). Respecto de la dimensión epistemológica, Grossberg (1996) señala que las luchas en torno a la identidad ya no implican cuestiones de adecuación o de distorsión, sino de la política misma de representación del otro. Por ello se advierte relevante integrar los planteamientos de teorías postcoloniales y feministas interseccionales que visualizan estos distintos tipos de violencia que operan desde la práctica científica tradicional y que apuestan por una "objetividad fuerte" asociada a la validación de un conocimiento situado y desde un "punto de vista desde abajo" (Haraway, 1995, p. 340), capaz de contrarrestar estas múltiples determinaciones.

Estas perspectivas consideradas posdualistas, permiten comprender la articulación y conjugación de estas subalternaciones y su impacto en los sujetos y colectivos que las experimentan (Lugones, 2008; Walsh, 2007). En tanto, busca recomponer y otorgar un lugar de protagonismo a movimientos y pensamientos latentes activamente ignorados, recuperando y recomponiendo sus historias (Santos, 2013) y memorias. En este mismo sentido, Rivera-Cusicanqui (2008) señala a la historia como una imposición hegemónica y un mecanismo de dominación necesario reelaborar, debido a que conforma también un "método colectivo de desalienación" (Rivera-Cusicanqui, 2008, p. 169). Advertimos entonces que a partir de estas perspectivas de conocimiento y metodológicas, es posible que múltiples voces e historias articulen horizontes de sentido que resguardan las sutilezas de sus propias necesidades y vivencias, desde un punto de vista situado. Desde donde, como plantea Rivera-Cusicanqui (2008), se impliquen tanto los sujetos protagonistas de la experiencia y el/ la investigador/a, como dos egos cognoscentes y simétricos, que a partir de la consciencia del lugar ocupado en la cadena colonial, se involucran en un proceso reflexivo de mutua implicación y trasformación, reconstrucción, descubrimiento, y de apertura a nuevas imaginaciones y horizontes de sentido (Rivera-Cusicanqui, 2008).

En síntesis, podemos afirmar que la sociedad moderna contemporánea ha creado mecanismos de control sofisticados de los sujetos a partir de la institución de nuevos procesos de subjetivación. Estos implicarían la constitución subjetiva e identitaria de los sujetos y pueden ser vivenciados de forma más o menos problemática, de acuerdo con la posición social, pertenencia étnico-cultural y género, modelando sus biografías e identidades en las trayectorias de vida. Vale considerar que en estos procesos los sujetos no tienen un rol absolutamente pasivo, sino que mediante su capacidad de agencia aportan elementos moduladores y creativos que forman parte del movimiento y cambio social. A su vez, desde las perspectivas poscoloniales integradas en el marco conceptual, se asume la dimensión del poder que atraviesa todas las dimensiones implicadas en el proceso de producción de conocimiento: esto es, la política de representación del otro, y la necesidad de desarrollar procesos que propendan a la visualización de estas dinámicas opresivas desde el proceso de interacción entre investigador/a y los sujetos sociales.

\section{Lineamientos metodológicos proyectados}

El marco teórico-conceptual configurado, proyecta lineamientos metodológicos que serán complementados con planteamientos de la fenomenología hermenéutica de Ricoeur (2006) y posestructuralistas. Tal articulación metodológica permitirá aprehender la complejidad que comportan los procesos de configuración identitaria de los jóvenes indígenas en la actualidad.

Ricoeur (2006) considera preferible hablar de individualización antes que de individuo, para señalar el hecho de que "la asignación de las individualidades pueda partir de grados muy variables de especificación (...) siguiendo los diferentes recursos léxicos de las lenguas naturales. Lo que es común a todas es la individualización, la operación antes que el resultado" (p. 2). Esta argumentación cobra relevancia cuando nos interesa comprender la configuración identitaria de un otro culturalmente diverso: el que porta en su repertorio simbólico-cultural una concepción del ser (sujeto-individuo) implicado en su medio comunitario y natural con una significación propia que justamente interesa comprender. 
Esta propuesta de abordaje metodológico, que para simplificar su mención llamaremos constructo, articula tres dimensiones: Macrosocial, Individualización narrativa e Interacción implicativa. La primera, comprende los procesos macrosociales que inciden en los mundos de la vida y experiencias de los sujetos. Estos corresponden a dinámicas sistémicas y estructurales que son significadas y absorbidas de forma colectiva e individualizada, instituyendo subjetividades en los distintos contextos de socialización en los que participan los sujetos, quienes internalizan estos flujos de significados a partir de su participación e implicación en aquellos. Por tanto, en la línea de lo propuesto por Appadurai, actúan cual "cascadas de acontecimientos locales y globales que van decantando en estructuras de sentimientos" (Appadurai, 2001, p. 161) e inciden en la estructuración normativa y subjetiva de los sujetos y colectivos. Estos procesos macrosociales corresponden a la tensión histórica entre los Estados y sociedades nacionales y los pueblos indígenas (Segato, 2002), políticas integracionistas y neocoloniales diseñadas desde el Estado, movimientos reivindicatorios y nuevos esencialismos étnicos (Bello, 2016; García-Canclini, 2005), mercantilización de las identidades, procesos de tecnologización y globalización (Castro-Gómez y Mendieta, 1998), movilidades y migración socioterritorial (Bello, 2007), entre otros. Estos se encarnan en las relaciones e interacciones sociales en las que participa el sujeto y su entorno próximo: entorno familiar, instituciones educativas, comunidad étnica de origen, comunidades religiosas, grupos de pares, etc. Por tanto, es factible identificar, ordenar y categorizar entre procesos distantes (o globales) y procesos cercanos (adoptados y significados) por el medio circundante.

Resulta importante visualizar de manera situada las dinámicas sociales que impulsan la emergencia de categorías-clivajes de diferenciación-identificación étnica-cultural, en la línea de lo propuesto por Appadurai (2001) quien propone que la cultura en lugar de corresponder a contenidos sustantivados, debe considerársele como adjetivo, ya que

Lo cultural facilita hablar de la cultura como una dimensión que refiere a diferencias, contrastes y comparaciones, permitiendo pensarla menos como una propiedad de los individuos y más como un recurso heurístico que podemos usar para hablar de la diferencia (p. 25).
Esta definición de lo cultural supone una dimensión que refiere a diferentes contrastes y comparaciones. A este respecto, García-Canclini (2005) señala que "el investigador no sería un especialista en una o varias culturas, sino en las estrategias de diferenciación que organizan la articulación histórica de rasgos seleccionados en varios grupos para tejer sus interacciones" (p. 39). El autor señala que "en las confrontaciones políticas es posible comprobar la utilidad de la cultura sustantivada como recurso estratégico para sostener reclamo" (p. 49). La reconceptualización hacia lo cultural, como adjetivo, no sustituye enteramente su uso sustantivado; sigue teniendo sentido para los actores sociales hablar de su cultura originaria en algunos casos para diferenciarse de la cultura nacional, pues "en distintas escalas, lo adjetivo sofistica o interseca el sentido sustantivado" (p. 49).

Para sintetizar esta dimensión podemos referir que subsume niveles macrosociales e intermedios (procesos colectivos) que forman parte de los mundos de la vida de los sujetos. Es importante para este análisis reconocer los contextos de socialización donde transita el sujeto desde una perspectiva diacrónica de trayectoria de vida, considerando el contexto poselectrónico (Appadurai, 2001) y digital por donde circulan, y son apropiados y recreados aspectos de la identidad y la diferencia.

La dimensión de individualización narrativa comprende las interpretaciones que realiza el sujeto desde la narración que realiza en primera persona en relación con sus experiencias individuales. A este respecto, Ricoeur (2006) propone la distinción de ipse (el sí mismo reflexivo) y mismidad (permanencia en el tiempo-invariante relacional) como dos valores constitutivos de la identidad personal, que se integran en una dialéctica que confluye desde un plano narrativo de primera persona. De acuerdo con Ricoeur (2006), la operación narrativa a diferencia del modelo causal, compagina las categorías consideradas contrarias entre sí: la identidad y la diversidad. Desde esta operación es el propio sujeto desde su relato quien configura la trama, el acontecimiento y su temporalidad.

Este postulado teórico-metodológico de la identidad narrativa, es complementada con los planteamientos teóricos de Deleuze (2005), quien define al sujeto como singularidad libre, es decir, "cualquier individuación es libre de re-configurarse, debido a su fondo meta-potencial" (p. 115). Este autor asume los postulados acerca de la individuación 
desarrollados por Simondon (1989), quien aborda la discusión metafísica en la identidad, señalando que la ontología clásica siempre ha tenido como fundamental el hecho de que hay formas cumplidas (esencias) que guían el movimiento y la evolución del ser. Así,

\begin{abstract}
se suponía que el cambio, el movimiento, no son más que deducciones a partir de esas formas primarias; por tanto las esencias vienen pensadas como causas y no como efectos. De esta forma, el movimiento y el proceso de individuación están entonces subordinados al individuo (Botto, 2011, p. 91).
\end{abstract}

Esta es la principal subversión programática de Simondon, "conocer al individuo mediante la individuación, en vez que la individuación a partir del individuo" (p. 92); la cuestión principal será, entonces, ¿cómo adviene el proceso de individualización?

Estos planteamientos son de sumo interés para configurar los lineamientos metodológicos aquí propuestos. Toda vez que releva la trayectoria, el proceso mediante el cual el sujeto se individualiza y construye su identidad. En esta línea Deleuze (2005) señala respecto de la tesis de Simondon (1989) que

\begin{abstract}
Al descubrir la condición previa a la individuación, distingue rigurosamente entre singularidad e individualidad. Lo metaestable, definido como un ser pre-individual, está perfectamente dotado de singularidades que corresponden a la existencia y al reparto de potenciales. [...] Singular, pero no individual, tal es el estadio de lo pre-individual. Es diferencia, disparidad (Deleuze, 2005, p. 116).
\end{abstract}

Por tanto se advierte que la relevancia del proceso trayectoria de vida se vincula con que en este es posible visualizar al sujeto preindividualizado, que comporta en sí con un plano o dimensión de lo potencial (cuerpo sin órganos), aquello que aún no se ha configurado, o que pudo y puede hacerlo, por tanto es latencia activa presta a emerger en articulación con las circunstancias específicas de la vida.

Para estos autores, cada individualización, entonces,

tiende a la configuración de una nueva personalidad, que es la liberación de unos potenciales del sujeto que antes estaban como atrapados (Simondon, 1989, traducido y citado en Botto, 2011, p. 112). Cada nueva individualización es descubrimiento y abertura hacia nuevos escenarios, cierre de los escenarios ya insatisfactorios, liberación de los potenciales (Botto, 2011, p. 113).

En esta dimensión entonces reside un espacio para avizorar, reconocer y desplegar los potenciales del sujeto adormecidos o reprimidos en su trayectoria de vida. Proponemos aquí que esto puede ser instigado a partir del diálogo y la exploración de los procesos individualizantes vivenciados por este en su trayectoria, todo ello es revelado a la conciencia del sujeto mediante la narrativa individual, planteo entonces, que esta potencialidad preindividual del sujeto que configura nuevas individualizaciones, puede ser precursado por la dinámica interactiva entre el investigador y el sujeto.

Y la tercera dimensión de interacción implicativa, comprende de manera situada el ciclo de interacciones que instaura la relación entre el/la investigador/y el sujeto en el contexto de indagación. Insta a observar de manera reflexiva la apertura del espacio de profundización de la narrativa del sujeto, comprendiéndolo como un espacio de reconstrucción de los procesos constitutivos de la identidad desde quien los ha vivenciado y vivencia. En este ejercicio el/la investigador/a asume el contexto como un espacio donde pueden ser avizoradas y desplegadas las potencialidades del ser, sus intensidades dormidas, que eventualmente pueden configurar nuevas posibilidades. En este sentido, Deleuze y Guattari (2004) plantean el movimiento de desterritorialización, de "comprender los movimientos de territorialización del sujeto en posiciones sociales colectivas y de desterritorialización en su devenir" (p. 291) y en este movimiento está implícito la contrarresta de las fuerzas opresivas sobre los sujetos, porque como señalan estos autores, el devenir siempre es minoritario, y arranca de una identidad mayor y hegemónica.

En esta línea de situar de manera reflexiva y critica el proceso investigativo, acogemos la perspectiva de la epistemología feminista, desde donde Haraway (1995) concibe y postula a la objetividad (a la que llama objetividad fuerte) como una búsqueda constante por abandonar la estructuración mutua y habitualmente desigual, reproducida desde el ejercicio científico considerado neutral. Para ello argumenta la necesidad de posicionar el proceso investigativo desde una perspectiva parcial o desde 
abajo (Haraway, 1995), la que se fundamenta por un lado, en la construcción situada de conocimiento, y por otro, en la premisa de que un conocimiento desde abajo permite obtener una mirada más objetiva de la realidad, al tensionar los relatos históricamente producidos desde lógicas que invisibilizan dinámicas opresivas, y avalan la posición de poder de los grupos dominantes: "La identidad no produce ciencia, el posicionamiento crítico sí, es decir, la objetividad" (Haraway, 1995, p. 340).

Entonces a partir del ciclo de interacciones implicativas entre investigador y sujeto, pueden abrirse espacios para la autoconciencia y recreación de su propia historia e identidad cultural individualizada, desplegar un nuevo protagonismo para la liberación de las múltiples opresiones, y destitución subjetiva a la que refiere Dufour (1998), propias de las sociedades modernas avanzadas.

Por tanto se propone que desde la dimensión interacción implicativa del constructo, asumir una posición "desde abajo" y situada desde la cual se abra un espacio para visualizar y promover la potencialidad del sujeto preindividualizado activando movimientos de desterritorialización producidos (de forma asumida y visible, o invisibilizada) en el propio proceso investigativo, para configurar el proceso como devenir y producir nuevas individualizaciones.
La dimensión interacción implicativa releva la contextualidad, lo situado y localizado de la producción de conocimiento y pone en relieve las relaciones de poder que intermedian el encuentro entre el investigador y el investigado, pero no solo desde la posición de poder específica que establece el encuentro interpersonal, sino desde el programa de investigación que se instala y despliega sobre la realidad, del que aquella es solo una de sus fases.

En este proceso cobra relevancia el principio de reflexividad que despliega el/la investigador/a consistente en una hermenéutica en dos direcciones o sentidos, una dialéctica del sí mismo y del otro (Ricoeur, 2006) que se pone en juego en la interacción entre sujeto investigador/a y sujeto partícipe. En tanto la interpretación del texto, requiere de la autoobservación como praxis constante y coextensa al proceso investigativo.

A partir de lo expuesto, podemos afirmar que estas dos últimas dimensiones referidas a la individualización narrativa y la interacción implicativa entre investigador/a y sujeto patícipe, en su conjunto pueden abrir un espacio para la expresión y despliegue potencial del ser, para recrear su identidad y activar un proceso generativo de una nueva individualización, por tanto emerge una propiedad creativa del constructo (ver Figura 1).

\section{Figura 1}

\section{Dimensiones del constructo metodológico}

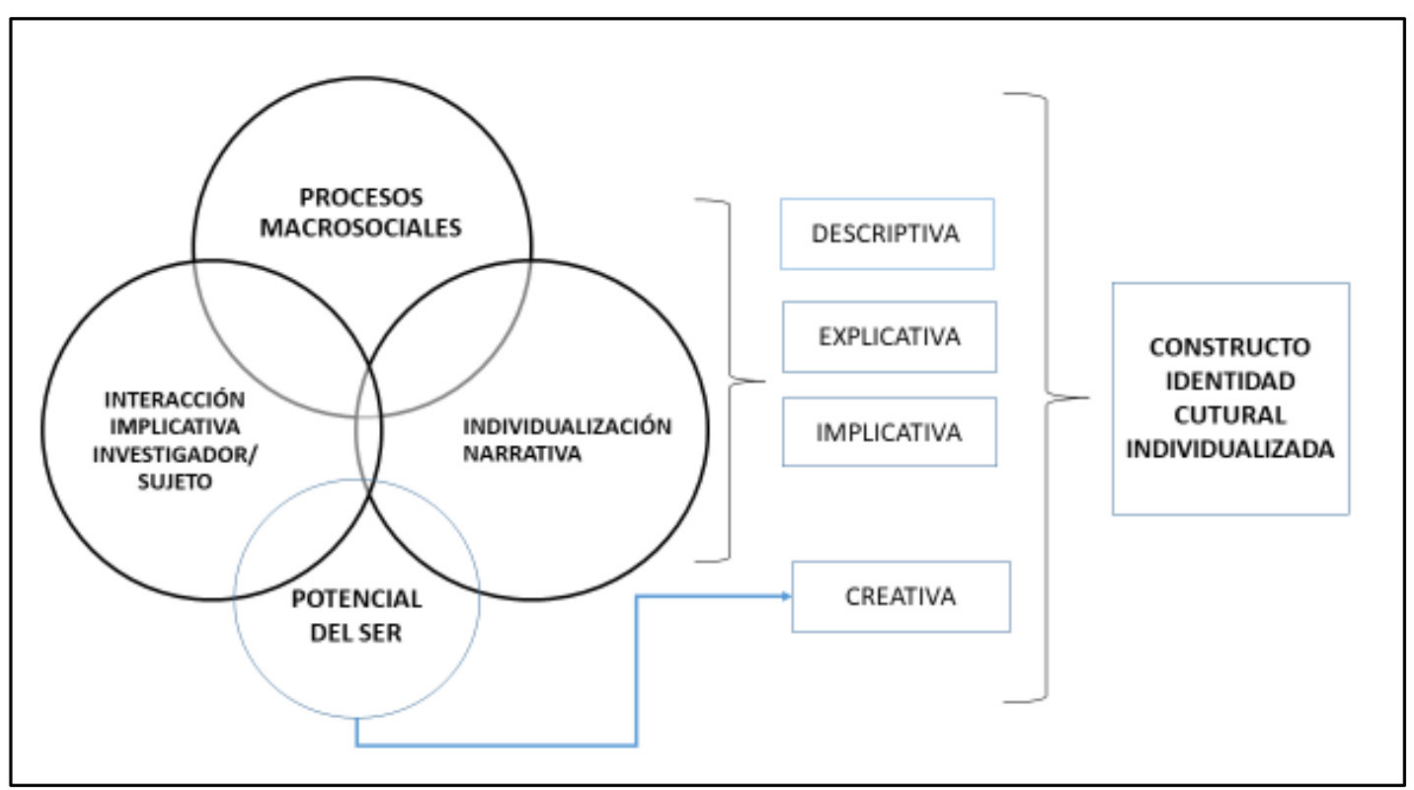

Elaboración propia 2021 
En síntesis observamos que cada una de las tres dimensiones que configuran el constructo apuntan a develar relaciones de opresión y dominación que forman parte de la construcción identitaria de los sujetos, y junto con comprender estos procesos de determinación, activa un principio de acción, que libera potencialidad y devenir. Por tanto el constructo presupone temporalidad, contiene diacronismo y movilidad, toda vez que en proceso reconstructivo de las trayectorias identitarias, se asume como un nuevo ciclo tendiente a la gestación de una nueva individualización. A partir de la activación de las potencialidades, e intensidades contenidas y adormecidas en esa historia de vida.

La nueva pregunta que emerge entonces es de qué forma es posible abordar la potencialidad para activar procesos de individualización liberadores del sujeto. Para ello las metodologías de acceso a la potencialidad (el espacio de inmanencia que enuncia Deleuze (1995)) tienen relación con un acercamiento multidimensional a los momentos constitutivos de la trayectoria preindividualizada con miras a reconocer y liberar las fuerzas y posibilidades reprimidas del ser desde la integralidad de su experiencia de vida, es decir, desde la razón, la imaginación, las emociones y el cuerpo y corporalidad. Al respecto Deleuze desde su propuesta del Cuerpo sin órgano, en la que releva la intensidad de la vivencia, advierte "sustituid la anamnesis por el olvido, la interpretación por la experimentación" (Deleuze y Guattari, 2004, p. 157). En esta cita, propone superar la interpretación, la invocación de fantasmas mentales que habitan en la memoria como fuente de representación. En cambio convoca a la creatividad, a la experimentación de formas de expresión. Abre múltiples oportunidades para explorar en las potencialidades del sujeto, posibilidades para el despliegue del ser y así contrarrestar las determinaciones coextensas a su historia.

Estos supuestos dialogan con los planteamientos de Foucault (2010) acerca del cuerpo utópico; quien reconoce al cuerpo dotado de significado, en tanto sustraído a los mundos simbólicos en los que se desenvuelve la experiencia de los sujetos, es lugar de disciplinamiento y ejercicio de poder, pero lo es también de potencia, se transforma en la posibilidad de conocimiento.

\section{Ensamblaje de resistencias y desarticulación de determinaciones}

Hasta aquí se asume entonces el proceso investigativo desde un esquema implicativo, performativo y situado. En el que se articula por un lado, la comprensión ecológica de procesos macrosociales, colectivo-comunitarios y de individualización, en donde se ensamblan resistencias, potencialidades y liberaciones para contrarrestar fuerzas opresivas. Ello a partir de perspectivas situadas "desde abajo" que revierten lógicas institucionalizadas de producción de conocimientos, los que al mismo tiempo afianzan y perpetúan relaciones de poder enquistadas en la propia producción de conocimiento (Harding, 1992). Asimismo, el visualizar las dinámicas macrosociales que producen múltiples niveles de opresión sobre los sujetos posibilita fortalecer discursos y comunicaciones desde posiciones de resistencia ante un poder hegemónico que amenaza de forma constante la superviviencia de las identidades étnico-culturales, visibilizando su incidencia e influjo en las propias historias de vida de los sujetos. Y un tercer ensamblaje, como ya ha sido señalado, se produce en la dimensión individualización narrativa, liberando el potencial contenido en las trayectorias de los sujetos y activando un nuevo proceso de individualización. En esta línea, respecto de las identidades, Langón (1989) señala que lo que debe encontrarse no es tanto un contenido esencial que sustantiviza y define a la identidad, sino más bien modos de identificación que muestren la presencia de un centro energético propio.

Desde la perspectiva de Deleuze y Guattari (2004) el constructo en su operativización activaría movimientos de territorialización, desterritorialización y devenir: "Solo hay sujeto del devenir como variable desterritorializada de la mayoría, y medium del devenir como variable desterritorializante de una minoría. Cualquier cosa, lo más inesperado, lo más insignificante, puede precipitarnos en un devenir" (p. 292).

Planteamos entonces, adoptando los términos de Deleuze (2004), que la activación de estos devenires se articulan configurando un rizoma de resistencia potencial y creativa. A su vez, observamos que esta reconfiguración de lo real, esta práctica de reversión del poder instituido, amplifica su radio de acción al afectar la intensidad presente y las futuras repeticiones y diferencias de las subsiguientes dinámicas de poder que definen a las minorías 
Figura 2

Movimiento de ensamblaje y desarticulación

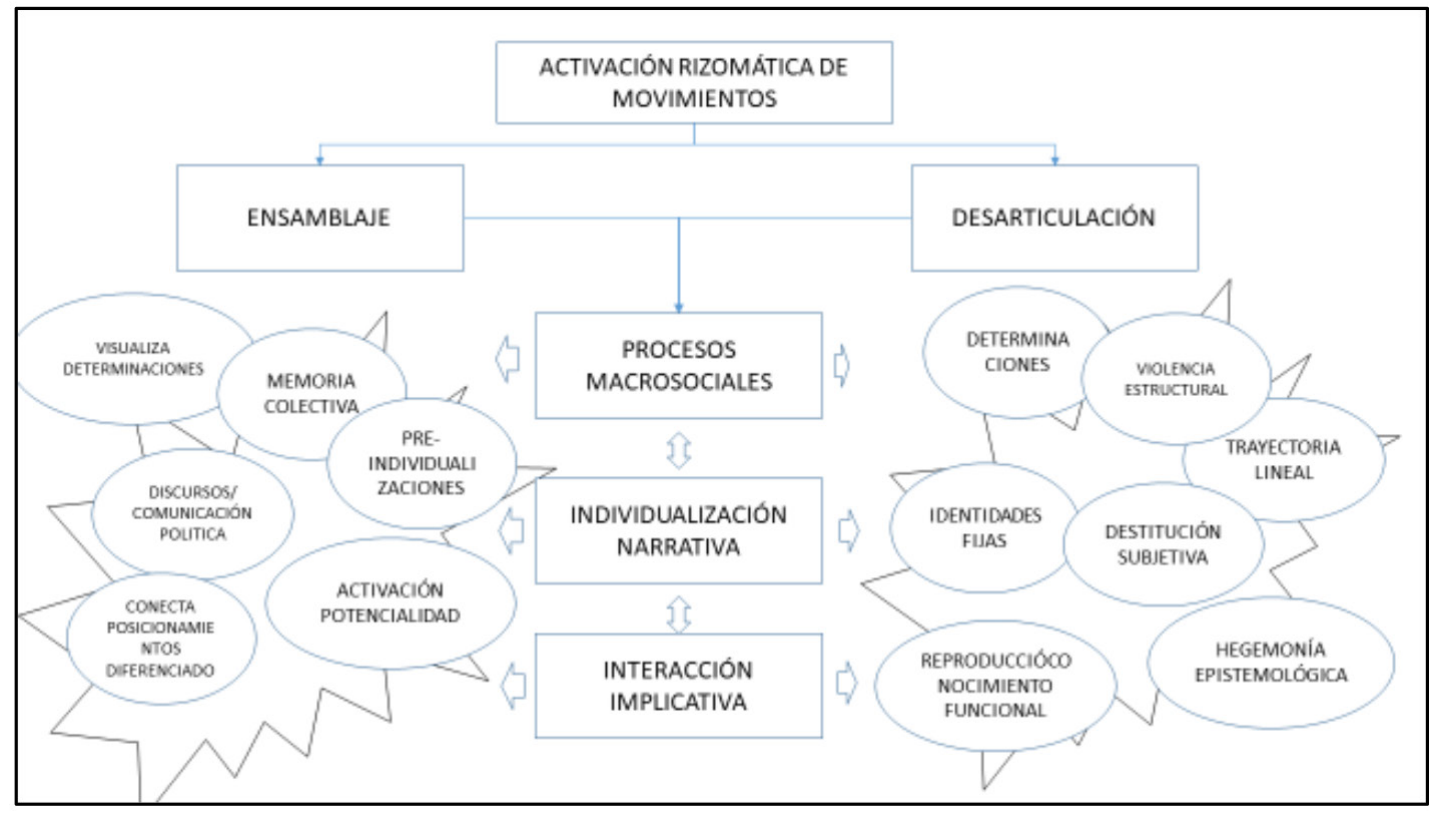

Elaboración propia 2021.

(subyugadas) y mayorías (patrones-hegemónicos) (Deleuze, 2004). En este contexto el constructo metodológico que se actualiza en su diferencia puede posicionarse como articulador-ensamblaje de fuerzas, experiencias y temporalidades abriendo espacios de potencialidad del sujeto investigado. Al mismo tiempo puede actuar como "desarticulador y neutralizador de las determinaciones, impulsando vinculaciones rizomáticas, conectando diversas formas de codificación" (Deleuze, 2004, p. 13). Para convertir a las distintas unidades implicadas en el proceso, tales como el sujeto y el investigador y sus entornos en devenir en direcciones múltiples, en el sentido de que para el autor, el devenir es la condición del ser en movimiento (Deleuze, 2004).

En esta línea consideramos relevante la problematización que se introduce desde la perspectiva posestructuralistas y las epistemologías feministas que develan y denuncian al ejercicio investigativo en la arena del poder y la producción de la verdad, cautelando la producción de un conocimiento que en palabras de Haraway (1995), ofrezca

una versión del mundo más adecuada, con vistas a vivir bien en él y en relación crítica y reflexiva con las propias prácticas de dominación y con las de otros y con las partes desiguales de privilegio y de opresión que configuran todas las posiciones (p. 321).

En la Figura 2 se ilustra el movimiento de ensamblaje y desarticulación que activa el constructo metodológico propuesto.

\section{DISCUSIÓN Y CONCLUSIONES}

A partir de los fenómenos actuales de configuración identitaria que vivencian los jóvenes pertenecientes a pueblos indígenas en Chile y Latinoamérica, en el contexto de la modernidad contemporánea y la globalización, así como de la discusión entre diversas perspectivas disciplinarias y teórico-metodológicas, desarrolladas respecto de las nociones de cultura e identidad, se ha propuesto un marco teórico-conceptual que permite aprehender las identidades étnico-culturales desde las trayectorias y narrativas de quienes las vivencian, visualizando las potencialidades y necesidades de complementariedad de los planteamientos de los autores citados. A este respecto, advertimos que la contraposición de argumentos y concepciones 
de cultura e identidad étnica-cultural ha permitido rescatar la heurística de las ideas de fondo donde se asientan, y con ello destacar la mirada de la praxis antropológica en estos desarrollos.

Desde esta articulación conceptual ha sido posible trazar líneas metodológicas y ensamblar un constructo cuyo propósito apunta a ampliar el rango de comprensión, e implicancias de la investigación acerca de los complejos procesos de construcción identitaria de jóvenes pertenecientes a pueblos indígenas, donde se despliega el ser, su esperanza y también su conflictividad y sufrimiento.

En este contexto, el interés ha estado puesto en visibilizar las distintas determinaciones opresivas que experimentan los sujetos en los procesos de individualización y avizorar nuevas formas de liberación, resistencia y agenciamiento. La consideración de estas perspectivas ha permitido articular una noción de identidad que ensambla distintos procesos en movimiento, referidos a los elementos estratégicos, posicionales y relacionales de las dinámicas de diferenciación/identificación frente a un otro, en el marco de dinámicas sociales asociadas al Estado y sociedad nacional, a procesos de globalización, y que a la vez autoobserva su propia producción. En este proceso en relevante reconocer el papel que adquiere el/la investigador/a en la interacción implicativa con el sujeto partícipe, quien más allá de registrar e interpretar los relatos, posibilita espacios para ampliar el radio de interpretación, desde la activación regulada de una conciencia reflexiva y liberadora.
Sin ánimo de profundizar de manera sistemática en este punto, ya que el objetivo propuesto no apuntaba en esta dirección, advertimos que esta discusión tiene sus raíces en la reflexión filosófica y ontológica; las distintas nociones respecto de la cultura y la identidad, han transitado entre una concepción del ser y de identidad sustanciales, de calco y recurrencias que han primado durante la modernidad, hacia una concepción de la diferencia, de lo múltiple, que releva la intensidad y la potencia; que organiza (y desorganiza) de diferente forma los elementos de la realidad, permitiendo que afloren nuevas formas y posibilidades de vivenciar para los sujetos, en un movimiento de adquisición de mayores niveles de consciencia, y también de liberación de intensidades y potencialidades adormecidas, anudando la realidad de forma diferente y por tanto implicando -en y a-sus entornos sociales. Como ya hemos señalado, en este ejercicio es imprescindible considerar una reflexión recursiva y simultánea de nuestro propio proceso como investigadores vinculantes de la producción de comprensiones o conocimientos. Atender al lugar de enunciación donde se coproduce la narrativa y el relato, lo que proyecta también discusiones futuras de índole epistemológica y metodológica.

Para finalizar y en relación con este último punto, queda abierta la discusión acerca de la viabilidad de estos presupuestos en niveles filosóficos, teóricos y metodológicos. Emerge la pregunta por las metodologías, formas de acercamiento a estas trayectorias que sean capaces de dar respuesta al desafío de ensamblar resistencias y desarticular determinaciones. 


\section{REFERENCIAS}

Aguirre Baztán, A. (coord.) (2020). Diccionario temático de antropología cultural. Madrid, España: Delta Publicaciones.

Aravena, A. (1999). Identidad indígena en los medios urbanos. Procesos de recomposición de la identidad étnica mapuche en la ciudad de Santiago. En Lógicas mestizas en América. Boccara, G.; Galindo, S; eds. Temuco, Chile: Instituto de Estudios Indígenas, 1999. 165-199.

Antileo, E (2011). Diáspora mapuche y multiculturalismo en Santiago. Revista Kütral.

Antileo, E. (2014). Lecturas en torno a la migración mapuche. Apuntes para la discusión sobre la diáspora, la nación y el colonialismo. En A. Fielbaum, R. Hamel y A. L. Dietz (Editores) El poder de la cultura. Espacios y discursos en América Latina (pp. 261-287). Santiago: Ediciones Facultad de Filosofía y Humanidades.

Appadurai, A. (2001). La modernidad desbordada. Dimensiones culturales de la globalización. Montevideo: Trilce-FCE.

Barth, F. (Comp.). (1976). Los grupos étnicos y sus fronteras. La organización social de las diferencias culturales (S. Lugo, Trad.). Fondo de Cultura Económica. (Obra original publicada en 1970).

Bello, A. (2007). Indigenous migrations in Chile: trends and processes. Indigenous Affairs, 03 (07), 6-17.

Bello, A. (2016). ¿Pertenencia o identidad? implicancias de dos categorías socioculturales para los derechos indígenas y la lucha contra el racismo. Revista Antropologías del Sur, 3 (6), 13-27.

Boas, F. (1964). Cuestiones fundamentales de Antropología cultural. Ediciones Solar, Buenos Aires, Argentina.

Botto, M. (2011). Sujeto e individuo en el pensamiento de Gilles Deleuze. Tesis Doctoral de Filosofía, Universidad Autónoma de Madrid. Dirigida por José Zamora Calvo.

Byung-Chul, Han. (2013). La sociedad de la transparencia. Barcelona, España: Herder.

Byung-Chul, Han (2018). Hiperculturalidad. Barcelona: Herder Editorial.

Castro-Gómez, S. y Mendieta, E. (1998). En teorías sin disciplina (Latinoamericanismo, poscolonialidad y globalización en debate). Edición de Santiago Castro-Gómez y Eduardo Mendieta. México: Miguel Angel Porrúa.

Deleuze, G. (2002). Diferencia y repetición. Buenos Aires, Argentina: Amorrortu.

Deleuze, G. y Guattari, F. (2004). Mil mesetas. Capitalismo y esquizofrenia. Valencia, España: Pretextos.

Deleuze, G. y Guattari, F. (1993). ¿Qué es la filosofía? Barcelona, España: Editorial Anagrama.

Deleuze, G. (2005). La isla Desierta y otros textos. Textos y entrevistas (1953-1974). Traducción de José Luis Pardo Torío. Valencia, España: Pretextos.

Deleuze, G. (1995). Inmanencia...una vida. Revista Philosophie $\mathrm{N}^{\circ} 47$, Minuit Paris, (3-7)

Dufour, D. (1998). Los desconciertos del individuo-sujeto. Le Monde Diplomatique, Ediciones Cono Sur, 11 de mayo 2001.

Foucault, M. (2008) [1981]. Vigilar y castigar. Nacimiento de la prisión. Buenos Aires, Argentina: Siglo Veintiuno Editores.

Foucault, M. (2010). El cuerpo utópico. Las heterotopías. Buenos Aires, Argentina: Ediciones Nueva Visión.
Foucault, M. 1988 [1982]. El sujeto y el poder. Revista Mexicana de Sociología, 50 (3), 3-20.

García Canclini N. (2004). Desiguales, diferentes y desconectados. Mapas de la Interculturalidad. Barcelona, España: Editorial Gedisa.

Geertz, C. (1987). La interpretación de las culturas. Barcelona, España: Editorial Gedisa.

Grimson, A. (2011). Los límites de la Cultura. Crítica de las teorías de la Identidad. Siglo Veintiuno Editores.

Hall, S. y Du Gay. P. (2003). Cuestiones de Identidad Cultural. Buenos Aires. Amorrortu Editores.

Haraway, D. J. (1995). Ciencia, cyborgs y mujeres. La reinvención de la naturaleza. Madrid, España: Cátedra.

Harding, S. (1992). Rethinking standpoint epistemology: What is "strong objectivity? The Centennial Review, 36 (3), 437-470.

Langón, M. (1989). ¿Qué tenemos que ver los unos con los otros? Rev. Nueva Sociedad 99, Enero-Febrero 1989. 137-146.

Kuper, A. (2001). Cultura. La versión de los antropólogos. Barcelona. Paidós.

Lugones, M. (2008). Colonialidad y género. Tabula rasa. Bogotá, Colombia. $\mathrm{N}^{\circ}$ 9. 73-101.

Marcuse, H. (1993). El hombre unidimensional. Ensayo sobre la ideología de la sociedad Industrial Avanzada. Barcelona, España: Editorial Planeta de Agostini.

Neigburg, F. y Goldman, M. (2001). Teoría, política y ética en los estudios antropológicos del carácter nacional. Alteridades, 11 (22), 95-110

Ortner, S. B. (1999). Thick Resistance: Death and the Cultural Construction of Agency in Himalayan Mountaineering, en S. B. Ortner (ed.), The fate of "Culture": Clifford Geertz and beyond (136-63). Berkeley/LosAngeles: University of California Press.

Poutignat, P. y Streiff-Fenart, J. (1995). Théories de l'ethnicité. Traducción de Gilberto Giménez. Presses Universitaires de France.

Ricoeur, P. (2006). El sí mismo como otro. México: Siglo XXI Editores.

Rivera-Cusicanqui, S. (2008). El potencial epistemológico y teórico de la historia oral En Teoría crítica dos direitos humanos no século XXI. Editado por A. Rosillo et al. Porto Alegre, Brazil: Edipucrs.

Rose, N. (1990). Governing the soul. The shaping of the private self. London and N. York: Routledge.

Santos, B. (2013). Descolonizar el saber, reinventar el poder. Santiago: LOM Ediciones.

Segato, R. (2002). Identidades políticas/ Alteridades históricas una crítica a las certezas del pluralismo global. RUNA, Archivo Para Las Ciencias Del Hombre, 23 (1), 239-275, https://doi. org/10.34096/runa.v23i1.1304

Simondon, G. (1989). L'individuation psychique et collective. Paris: Aubier.

Walsh, K. (2007). ¿Son posibles unas ciencias sociales/culturales otras? Reflexiones en torno a las epistemologías decoloniales. Nómadas, 26. 102-113. 